ISSN 1984-3755

\title{
Cursos de Pedagogia e o Ensino Religioso: um debate necessário
}

Religious Education and Pedagogy courses: a necessary debate

\section{Lourival José Martins Filho}

Doutorado em Teologia na área de concentração em Educação e Religião pela EST/RS, professor associado do Departamento de Pedagogia e Diretor de Ensino do Centro de Ciências Humanas e da Educação - FAED da Universidade do Estado de Santa Catarina (UDESC), Florianópolis, SC - Brasil, e-mail: lourivalfaed@gmail.com

\section{Resumo}

O artigo é decorrente de um projeto de investigação em andamento no Programa de Pós-Graduação em Teologia da Pontifícia Universidade Católica do Paraná que objetiva prioritariamente analisar, nos projetos pedagógicos dos cursos de Pedagogia de um Estado da Região Sul do Brasil, evidências do componente curricular Ensino Religioso no processo de formação docente para a educação básica. Sabemos que, aprovada pelo Conselho Nacional de Educação, em 15 de maio de 2006, a Resolução CNE/ CP n. 1, que institui as Diretrizes Nacionais para o Curso de Graduação em Pedagogia, licenciatura, é um belo exemplo dos enfrentamentos e dissensos que podem ser gerados nas disputas curriculares. Destacamos que, no âmbito dessa Resolução não aparece o Ensino Religioso como uma das atribuições de docência do pedagogo como em outras áreas de conhecimento. As análises e reflexões no momento da pesquisa apontam a necessidade de qualificar os cursos de Pedagogia no Brasil, responsáveis 
pela formação do professor, já que tais propostas têm obliterado os temas relacionados ao Ensino Religioso.

Palavras-chave: Formação docente. Ensino Religioso. Anos iniciais do ensino fundamental.

\section{Abstract}

The article is the result of an ongoing research project within the Graduate Program in Theology at the Catholic University of Parana, which primarily aims to analyze the evidence of Religious Education curriculum component in teacher training process for basic education in pedagogical projects of Pedagogy courses of a southern state in Brazil. We know that the Resolution CNE/CP n. 1, on May 15, 2006, approved by the National Council of Education, that establishes the National Guidelines for Undergraduate Formation in Pedagogy, teacher training major, is a good example of the conflict and dissension that can be generated in curricular disputes. We highlight that Religious Education does not appear under this Resolution as one of the teaching attributions of the teacher as it does in other areas of knowledge. The analyses and reflections in this moment of the research indicate the need of qualifying the Pedagogy courses in Brazil, which are responsible for teacher training, since such proposals have obliterated the issues related to Religious Education.

Keywords: Teacher training. Religious Education. First years of elementary school.

Este artigo apresenta algumas reflexões teórico-metodológicas no que diz respeito à formação de professores, especialmente para os anos iniciais do ensino fundamental, e reúne algumas reflexões para se pensar a prática pedagógica, tendo como objeto de análise o componente curricular Ensino Religioso e sua vinculação com os cursos de Pedagogia.

Nossa reflexão faz parte de um projeto de investigação em andamento no Programa de Pós-Graduação em Teologia da Pontifícia Universidade Católica do Paraná que objetiva, prioritariamente, analisar, nos projetos pedagógicos dos cursos de Pedagogia de um Estado da Região Sul do Brasil, evidências do componente curricular Ensino Religioso no processo de formação docente para a educação básica. 
Registramos que compreender esse processo, para os pesquisadores que investigam a construção das práticas curriculares na área de Ensino Religioso, pode contribuir significativamente na formação inicial dos cursos de Pedagogia.

Nessa direção, o trabalho, como parte da pesquisa em andamento, focará neste artigo a necessidade do componente curricular Ensino Religioso como parte integrante das dimensões conceituais das matrizes curriculares dos cursos de Pedagogia, na medida em que, em âmbito nacional, este é o curso que possibilita o ingresso de milhares de docentes no exercício profissional nos anos iniciais da educação básica.

Sabemos que, aprovada pelo Conselho Nacional de Educação, em 15 de maio de 2006, a Resolução CNE/CP n. 1, que institui as Diretrizes Nacionais para o curso de Graduação em Pedagogia, licenciatura, é um belo exemplo dos enfrentamentos e dissensos que podem ser gerados nas disputas curriculares. Destacamos que, no âmbito dessa Resolução, não aparece o Ensino Religioso como uma das atribuições de docência do pedagogo como em outras áreas de conhecimento. Nossa experiência revela, porém, que, cada vez mais egressos dos cursos de Pedagogia, ao ingressarem no mercado de trabalho, seja na iniciativa privada como em unidades públicas de ensino, se deparam com essa área do currículo para lecionarem e, na maioria das vezes, assumem uma postura preconceituosa ou de grande ansiedade por não conhecerem as discussões atuais.

Um participante da pesquisa, que atua como docente nos anos iniciais do ensino fundamental numa escola da Grande Florianópolis, assim relata:

Gente quando cheguei na escola e a coordenação pedagógica me falou que teria que lecionar Ensino Religioso fui logo dizendo que o estado é laico e que não aprendi nada para ensinar. Depois pensei que bastaria realizar orações com as crianças. Como me enganei hoje atuando há cinco anos na mesma escola percebo o Ensino Religioso como uma importante disciplina que reconhece todas as manifestações religiosas numa perspectiva sempre plural e nunca mais de catequese (Pedagoga - Participante A).

Como pesquisadores da área do Ensino Religioso, precisamos evidenciar nos fóruns e debates nacionais em educação a necessidade de implantarmos licenciaturas específicas para a docência do componente 
curricular Ensino Religioso. Ressaltamos, entretanto, que a formação em Pedagogia garante por força de lei a docência nos anos iniciais do ensino fundamental, sendo que não podemos falar mais em inclusão, se não garantirmos que no seu processo formativo o pedagogo também se aproprie desse saber definido também por lei como componente curricular e área de conhecimento.

Destacamos também que as Diretrizes Nacionais para o Curso de Graduação em Pedagogia sofreram críticas de vários grupos, ao mesmo tempo em que eram exultadas por outros. No bojo desse debate, vimos, com a sua aprovação, ser implementado um modelo de formação para o curso de Pedagogia que modificava significativamente as práticas até então vividas e materializadas pelas Universidades. Anterior a 2006 os cursos de Pedagogia tinham a formação prevista por habilitações. Isso significava que, a partir de uma fase do curso, o acadêmico escolhia a área em que queria se aprofundar para atuar. Tínhamos as habilitações: Educação Infantil, Educação Especial e Orientação Educacional, entre outros.

Numa leitura atenta da Resolução já mencionada, importa destacar que, em essência, as Novas Diretrizes da Pedagogia pautam a formação do pedagogo para a docência e a gestão.

Conforme seu Art. $2^{\circ}$ :

As Diretrizes Curriculares para o curso de Pedagogia aplicam-se à formação inicial para o exercício da docência na educação infantil e nos anos iniciais do ensino fundamental, nos cursos de ensino médio, na modalidade Normal, e em cursos de educação profissional na área de serviços e apoio escolar, bem como em outras áreas nas quais sejam previstos conhecimentos pedagógicos.

As diretrizes definem que o curso de graduação em Pedagogia deve se estruturar a partir de um núcleo básico que, preservando a diversidade e a multiculturalidade da sociedade brasileira, possa articular, dentre outros, princípios da gestão democrática contemplando os espaços escolares e não escolares; conhecimento humano na sua multidimensionalidade; reconhecer os diferentes interesses dos segmentos sociais que compõem a sociedade; observação do contexto histórico e sociocultural brasileiro e suas implicações para o entendimento da educação infantil, do ensino 
fundamental e da formação de professores e de profissionais na área de serviço e apoio escolar; apreensão das relações entre educação e trabalho e outras questões da sociedade contemporânea; articulação do saber acadêmico, da pesquisa, da extensão e da prática educativa às questões relativas à ética, à estética e ao lúdico. São previstos também um núcleo de aprofundamento de estudos e um núcleo de estudos integradores.

Destaca-se, porém, que a referida Resolução não evidencia a contribuição que o Ensino Religioso pode oportunizar num cumprimento de seus princípios e objetivos.

Registramos ainda que, com o surgimento da Lei 9.475/97, que dá nova redação ao artigo 33 da LDBEN 9.394/96, o Ensino Religioso deixou de ser confessional, exigindo uma radical transformação de sua maneira de compreendê-lo e administrá-lo (BRASIL, 1997).

A questão no âmbito das universidades e especialmente das Faculdades de Educação passa, sobretudo, por repensar a estrutura departamental que torna os currículos tão engessados e hierarquizados que a questão da formação docente e dos anos iniciais do ensino fundamental, incluídas as áreas de conhecimento História, Geografia e Ensino Religioso, é muitas vezes suprimida pela própria estrutura burocrática criada em torno dos docentes universitários. Pensar a formação docente para a diversidade cultural religiosa tão intensa no Brasil vai exigir também que os professores das instituições de ensino superior tenham humildade de transpor as fronteiras de suas disciplinas, no sentido de dialogarem sobre as necessidades formativas tão presentes no contexto dos professores da educação básica.

Paulo Freire (1997) alertou sobre a necessidade de o docente, em qualquer nível e modalidade de ensino, fazer de sua atuação um espaço de aprendizagem e cumplicidade. A formação inicial no âmbito dos cursos de Pedagogia precisa oportunizar discussões que estão pulsantes no contexto das políticas e práticas do Ensino Religioso, produzindo conhecimentos por meio de ações de pesquisa e extensão.

Essa é uma questão fundamental e traz implicações diretas para os anos iniciais de ensino do ensino fundamental. Em relação ao Ensino Religioso, não cabe mais a contestação de seu espaço ou não na escola. Até porque: 
O Ensino Religioso alicerça-se nos princípios da cidadania, do entendimento do outro enquanto outro, de formação integral do educando. Pois, ainda que muitas pessoas neguem ser religiosas, é um dado histórico, toda pessoa é preparada pra ser religiosa, do mesmo modo que é preparada para falar determinada língua, gostar disto ou daquilo, comer, vestir-se de uma forma, acreditar ou não, pois o ser religioso é um dado antropológico, cultural. No substrato de cada cultura sempre está presente o religioso (FERNANDES, 2000, p. 70).

A formação em Pedagogia é uma urgência vital para o desenvolvimento do país, já que o êxito do processo de alfabetização depende, em grande parte, da competência pedagógica dos professores.

Neste ponto, gostaríamos de reafirmar a tese de Lúria (1989), no sentido de que o processo da alfabetização na criança começa muito antes da primeira vez em que o professor coloca um lápis em sua mão e lhe mostra como formar letras. Isso vale também para o Ensino Religioso, pois é um componente essencial na vida de todo ser humano, principalmente da criança. E, como fonte de desenvolvimento, contribui para a criatividade e para o crescimento intelectual, social, emocional e religioso do indivíduo (STEFFENS; KLEIN, 2005, p. 159). Ao desenvolver o Ensino Religioso pretende-se formar seres espontâneos, vivos, dinâmicos, capazes de exteriorizar seus pensamentos, seus sentimentos e suas sensações e de utilizar diversas formas de linguagens.

Tendo em vista a realidade brasileira em relação à formação de professores para os anos iniciais do ensino fundamental, permite-nos afirmar que é necessário superar a restrição da mera aquisição de conhecimentos específicos, redimensionando a formação para um sentido mais amplo. Ou seja, uma formação que abarque as dimensões: intelectual, humana e cultural. Isto tanto em relação aos professores formadores, como para os professores em formação inicial.

Essa preocupação parte da premissa de Paulo Freire (2005, p. 23) de que o mundo não é, o mundo está sendo. Neste sentido, a história e o ser humano e as práticas pedagógicas não podem ser vistos numa visão determinista, absoluta ou fatalista. É a esperança sempre crítica e engajada que define o fazer docente para além de uma atividade neutra e sem compromisso. 
Vivemos em uma fase de transição, de mudança de paradigmas em todos os âmbitos do humano. Atualmente parece-nos necessário a todo tempo falar de transformações, mudanças, momentos de transição, etc. Para a sociedade contemporânea, as mudanças são decorrentes dos avanços das pesquisas científicas em todos os campos do conhecimento, que, atreladas ao avanço do capitalismo, nos impõem uma lógica de ação cada vez mais dependente das relações mercadológicas.

Nossa premissa caminha no sentido de relacionar letramento, alfabetização e Ensino Religioso, dimensões consideradas indissociáveis e complementares quando se pretende educar as crianças dos anos iniciais.

Neste caso, cabe afirmar que ler é uma prática do letramento e a escola é uma das principais agências de letramento, tendo a função de transmitir o conhecimento sistematizado e, por conseguinte, o ensino do sistema de escrita e leitura. O Ensino Religioso insere-se, nesse contexto, como conhecimento historicamente construído e possível de ser transmitido de forma crítica e criativa às novas gerações.

Registramos, ainda, que a universalização do acesso ao ensino fundamental é um desafio para o país, uma vez que apresenta uma elevada exclusão social. Porém, pelos dados apresentados pela educação nos últimos anos, o desafio maior é com a qualidade do ensino. Desafio político-pedagógico do governo e da sociedade e que requer elevados investimentos com recursos humanos, materiais, financeiros, com destaque para os tecnológicos (SANDER, 2006, p. 17).

Essa discussão no âmbito do Ensino Religioso se fortalece ainda mais, pois sabemos que é área de conhecimento, devendo estar presente nos currículos educativos. "No processo da educação, o Ensino Religioso tem sua parcela de contribuição para a formação do cidadão, independente da raça, cor, cultura e religião ao direito de participação na construção do exercício da cidadania" (FUCHS, 2005).

Assim, consideramos o Ensino Religioso no processo de alfabetizar letrando como um dos saberes fundamentais que possa contribuir na feitura de um mundo mais inclusivo.

Mesmo com essa convicção, destacamos a seguir partes de um depoimento de um coordenador de curso de Pedagogia de uma instituição de educação superior do sul do país. 
Sabe Professor Lourival sendo bem sincera com você, considero que você está perdendo o seu tempo com uma pesquisa como esta. O Ensino Religioso só tem validade na cabeça de vocês. Não acredito que os colegiados de ensino dos cursos de Pedagogia vejam essa disciplina com o destaque que ela merece. No nosso curso falamos de forma bem superficial de diversidade religiosa em algumas ementas, mas aí a chegar na dimensão do Ensino Religioso como conhecimento que o pedagogo também tem que ensinar tão pedindo demais (Coordenador de curso de Pedagogia - Participante B).

Conforme já explicitamos, evidencia-se que a forma de se organizar um currículo está estritamente vinculada à intencionalidade educativa de quem o sistematiza e o coloca em prática. Sendo assim, nossa tentativa em buscar vincular o Ensino Religioso à proposta curricular dos cursos de Pedagogia segue o caminho de unir o proposto (estamos nos referindo às concepções, às ideias e às intenções) com o vivido (estamos nos referindo às experiências cotidianas).

É imperioso destacar que

entendemos que somente o compromisso no processo por parte de educadores e educadoras, gestores responsáveis e pesquisadores(as), em conexão com os anseios da população, poderá despertar a seriedade com que deve ser tratada e discutida a docência em Ensino Religioso no âmbito dos anos iniciais do ensino fundamental, o que passa necessariamente por redefinição de políticas públicas, diretrizes curriculares, formação e valorização docente (MARTINS FILHO, 2008, p. 170).

Novamente tomando as análises de Paulo Freire (1993), podemos afirmar que estes tempos de transição e mudança produzem nos professores uma anestesia histórica e um cansaço existencial. Percebe-se, na educação básica como na educação superior, um reflexo destas duas premissas do autor. Vivemos, na educação básica, certa ausência de produção de conhecimentos por parte dos docentes e na educação superior um exagero para atendimento das novas lógicas dos órgãos de fomento, o que gera em muitas situações produção de saberes vazios de sentido e significados. O depoimento do coordenador participante da pesquisa revela total desconhecimento da história, da legislação e dos fundamentos do Ensino Religioso no Brasil. 
Ora, o Ensino Religioso enquanto disciplina integra-se à reflexão e à organização pedagógica da escola e com ela colabora executando a parte que lhe cabe no processo: dar vida aos elementos curriculares dentro de sua realidade específica (BRANDENBURG, 2004, p. 58).

Nosso principal argumento sobre a necessidade de lançarmos um olhar crítico e investigativo para as propostas curriculares dos cursos de Pedagogia é pelo fato de o currículo ser considerado o provocador de intencionalidades e necessidades. Para nós,

[...] o Ensino Religioso, no processo educativo, é um dos canais concretos que poderá contribuir com o processo de humanização e respeito, que não "coisifica" o outro, mas o edifica na condição de seu direito à liberdade de ser humano (OLENIKI; DALDGAN, 2004, p. 10).

Concordamos com Martins Filho (2008, p. 10-13) no sentido de tecermos uma defesa à ampliação do repertório de conhecimentos tanto de âmbito teórico como prático nos processos de formação de professores. Acreditamos que a ampliação do universo cultural, intelectual e humano dos professores possibilita que suas práticas se aproximem cada vez mais das demandas sociais que vão apresentando-se ao longo de sua profissão e permitem que a reflexão crítica se instale em suas práticas cotidianas.

Assumir o Ensino Religioso na perspectiva da formação, da busca de um significado de vida, do desenvolvimento da personalidade, do compromisso com a plena realização, tem implicações com os conteúdos e as metodologias veiculadas. Isto é, exige-se a coerência e a consistência entre teoria e prática, intenções e ações, o que perpassa pela transformação de seu articulador, de seu interlocutor, de seu mediador que é a pessoa do educador, o professor de Ensino Religioso como catalisador pela sua sensibilidade, perspicácia e criatividade (JUNQUEIRA, 2004, p. 35).

Cardoso (2004) defende uma educação que abra corações e mentes e que, ao mesmo tempo, possa desenvolver a sensibilidade, a sutileza, os valores humanos, a consciência crítica e a própria humanidade em cada sujeito. Percebemos que não desvaloriza a figura do professor e/ou do processo educativo que envolve o ensino e a aprendizagem, ao contrário, luta contra o empobrecimento ou mesmo o esvaziamento dos sentidos mais próprios e amplos do conhecimento. Assim, defende que o homem 
deveria poder ser dotado de múltiplas aptidões, tanto manuais quanto intelectuais, e este deveria ser o objetivo das práticas educativas. Em nosso entendimento o Ensino Religioso pode contribuir para a formação cidadã na medida em que o fenômeno religioso está presente em todas as dimensões da vida humana, podendo ser historicizado e ensinado.

Parece-nos que conhecer a realidade e a produção teórica do Ensino Religioso seja um dos desafios para os elaboradores de propostas de formação de professores no nosso imenso e diversificado Brasil.

Como Nóvoa (2002), ressaltamos quatro pontos que a autor apresenta como desafios para se pensar a renovação dos processos de formação docente. Tal análise nos auxilia a clarear propostas que reconciliem a escola com a sociedade e chamem a sociedade a uma maior presença na escola. Em primeiro lugar, o autor chama atenção para que a educação não exclua a "contemporaneidade", reduzindo-se apenas às formas clássicas de conhecimento. Em segundo lugar, contrariar tendências de desvalorização do conhecimento; a Pedagogia está indissociavelmente ligada aos conteúdos de ensino. Em terceiro lugar, admitir novas formas de relação ao saber; a realidade atual do mundo da ciência e da arte define-se por uma complexidade e uma imprevisibilidade que a escola não pode continuar a ignorar. Em quarto e último lugar, compreender o impacto das tecnologias da informação e da comunicação, que transportam formas novas de conhecer e de aprender. Fica evidente que o Ensino Religioso pode contribuir na formação inicial de professores para os anos iniciais do ensino fundamental, alargando sua visão de mundo e reconhecendo o sagrado como forma também de leitura da realidade.

Para Martins Filho (2005, p. 160) cabe ao professor resistir à tendência de transformar em fácil a tarefa de tornar-se professor, num momento no qual as políticas educacionais convergem para a formação aligeirada e totalmente alienada dos processos políticos, econômicos e sociais que colocam em xeque não só a "educação para todos", como também uma "formação para todos", na medida em que a garantia da formação será dada aqueles que puderem comprá-la. Não podemos mais falar em Inclusão e Direitos Humanos e negar ao pedagogo em formação a oportunidade de conhecer dimensões conceituais fundamentais do Ensino Religioso que lhe servirão de base inicial para a docência nesta área. 
Acreditamos, como Paulo Freire (1974), que ser professor atualmente consiste em criticamente estar aberto ao mundo e compreendê-lo, atuando coletivamente, a fim de transformá-lo. Assim, em nosso entendimento

[...] é fundamental que o educador das séries iniciais integre o Ensino Religioso, pois o mesmo deve ser o mediador entre o educando e o conhecimento religioso. A relação interpessoal deve ser respeitosa, saudável, amigável, cordial e clara entre ambos, evitando o autoritarismo, para assumir um caráter de autoridade competente. A interação é um processo muito importante no processo de ensino-aprendizagem (WACHS, 2007, p. 70).

Já Tardif (2000) nos apresenta um requisito essencial para interligarmos a nossa análise da organização do trabalho pedagógico, qual seja: trabalhar em prol da coletividade, da reciprocidade e da aprendizagem relacional, em que seja possível pensarmos em processos educacionais que compartilhem experiências, ampliando os saberes por meio do diálogo e da parceria mútua entre os diversos sujeitos participantes do processo. Pensar nas relações sociais como eixo central para o exercício do trabalho pedagógico é trazer algumas sendas para novas atribuições no que se refere à prática educacional dos professores, bem como redefinir a função social das instituições de ensino superior, em especial aos cursos de Pedagogia, que formam professores para alfabetizarem em todas as áreas curriculares. Insira-se neste contexto o Ensino Religioso.

Por isso, entendemos que, se

o Ensino Religioso faz parte dos saberes que contribuem para a formação do cidadão, não pode ficar marginalizado na escola. A começar na formação inicial de pedagogos para atuarem como docentes na educação infantil e anos iniciais do ensino fundamental (CORDEIRO, 2004, p. 31, grifo nosso).

É imperioso qualificar os cursos de Pedagogia no Brasil, responsáveis pela formação do professor, já que tais propostas têm obliterado os temas relacionados ao Ensino Religioso. Vimos que, desde o início de sua formação, os professores se veem diante de uma lacuna, o que posteriormente gera uma resistência, a qual os leva a uma negação em trabalhar 
com os conhecimentos específicos do campo teórico do Ensino Religioso. O dialogo está aberto!

\section{Referências}

BRANDENBURG, L. E. A interação pedagógica no ensino religioso. São Leopoldo: Sinodal, 2004.

BRASIL. Lei n. 9475, de 22 de julho de 1997. Dá nova redação ao art. 33 da Lei n. 9.394, de 20 de dezembro de 1996, que estabelece as diretrizes e bases da educação nacional. Diário Oficial [da] República Federativa do Brasil, Poder Legislativo, Brasília, DF, 22 jul. 1997. Disponível em: <http://www.pedagogiaemfoco.pro.br/19475_97.htm>. Acesso em: 15 mar. 2008.

CARDOSO, M. L. Questões sobre educação. In: GOULART, C. (Org.). Dimensões e horizontes da educação no Brasil. Niterói: EdUFF, 2004.

CORDEIRO, D. A evolução dos paradigmas e o ensino religioso. In: SILVA, V. da. (Org.). Ensino religioso: educação centrada na vida: subsídios para a formação de professores. São Paulo: Paulus, 2004. p. 34-43.

FERNANDES, M. M. S. Afinal, o que é o ensino religioso? São Paulo: Paulus, 2000.

FREIRE, P. Cartas a Cristina. São Paulo: Paz e Terra, 1974.

FREIRE, P. Pedagogia da esperança. São Paulo: Paz e Terra, 1992.

FREIRE, P. Pedagogia da autonomia. São Paulo: Paz e Terra, 1997.

FUCHS, H. L. (Org.). Ensino religioso na escola: bases, experiências e desafios. São Leopoldo: Oikos, 2005.

JUNQUEIRA, S. R. A. O ensino religioso no contexto da educação. In: JUNQUEIRA, S.; WAGNER, R. (Org.). Ensino religioso no Brasil. Curitiba: Champagnat, 2004. p. 27-54.

LURIA, A. R. O desenvolvimento da escrita na criança. In: VYGOTSKY, L. S.; LURIA, A. R.; LEONTIEV, A. N. Linguagem, desenvolvimento e aprendizagem. São Paulo: Ícone; EDUSP, 1989. p. 30-38. 
MARTINS FILHO, L. J.; WACHS, M. C. (Org.). O ensino religioso e a decência nas séries iniciais do ensino fundamental: inquietações iniciais. In: KLEIN, R.; BRANDENBURG, L. E.; WACHS, M. C. (Org.). O ensino religioso: diversidade e identidade. In: SIMPÓSIO DE ENSINO RELIGIOSO, 5., 2008, São Leopoldo. Anais... São Leopoldo: Sinodal; EST, 2008.

MARTINS FILHO, A. J. (Org.). Criança pede respeito: temas em educação infantil. Porto Alegre: Mediação, 2005.

MARTINS FILHO, A. J. O lugar da criança. Pátio educação infantil, v. 6, n. 17, p. 10-13, 2008.

NÓVOA, A. Formação de professores e ação pedagógica. Lisboa: Educar, 2002. OLENIKI, M. L. R.; DALDGAN, V. M. Encantar: uma prática pedagógica no ensino religioso. Petrópolis: Vozes, 2004.

SANDER, B. Políticas educacionais e seus desdobramentos para a gestão da escola. In: SIMPÓSIO CATARINENSE DE ADMINISTRAÇÃO DA EDUCAÇÃO AAESC, 23., 2006. Camboriú. Anais... Camboriú: AAESC, 2006. p. 17.

STEFFENS, M. P.; KLEIN, R. A primeira infância e o ensino religioso: encontro essencial. In: FUCHS, H. L. et al. Ensino religioso na escola: bases, experiências e desafios. São Leopoldo: Oikos, 2005. p. 155-160.

TARDIF, M. Saberes docentes e formação profissional. 2. ed. Petrópolis: Vozes, 2000.

WACHS, M. C. A didática do ensino religioso em cursos de formação de professores de ensino médio. In: WACHS, M. C. et al. (Org.). Práxis do ensino religioso na escola. In: SIMPÓSIO DE ENSINO RELIGIOSO, 4., 2007, São Leopoldo. Anais... São Leopoldo: EST; Sinodal, 2007.

Recebido: 29/11/2011

Received: 11/29/2011

Aprovado: 15/02/2012

Approved: 02/15/2012 